\title{
Optimal management of idiopathic scoliosis in adolescence
}

This article was published in the following Dove Press journal:

Adolescent Health, Medicine and Therapeutics

22 July 2013

Number of times this article has been viewed

\section{Tomasz Kotwicki' \\ Joanna Chowanska ${ }^{1,2}$ \\ Edyta Kinel ${ }^{3}$ \\ Dariusz Czaprowski ${ }^{4,5}$ \\ Marek Tomaszewski' \\ Piotr Janusz' \\ 'Department of Pediatric Orthopedics, University of Medical Sciences, Poznan, Poland; ${ }^{2}$ National Scoliosis Foundation, Stoughton, MA, USA; ${ }^{3}$ Department of Rehabilitation, University of Medical Sciences, Poznan Poland; ${ }^{4}$ Department of Physiotherapy, Józef Rusiecki University College, Olsztyn, ${ }^{5}$ Rehasport Clinic, Poznan, Poland}

Video abstract

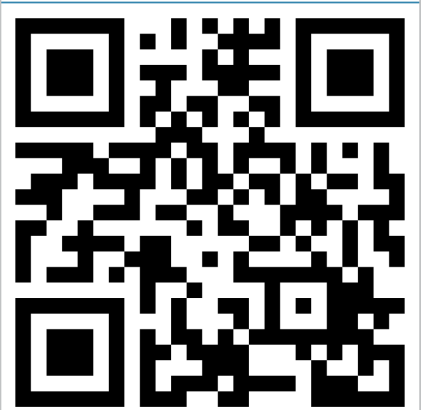

Point your SmartPhone at the code above. If you have a $Q R$ code reader the video abstract will appear. Or use: http://dvpr.es//3wxS9G

Correspondence: Tomasz Kotwicki Department of Pediatric Orthopedics, University of Medical Sciences, University of Medical Sciences, UI 28 Czerwca 1956 Roku Nr 135, Poznan 6I-545, Poland Tel +48618310360

Fax +48618310173

Email kotwicki@ump.edu.pl
Abstract: Idiopathic scoliosis is a three-dimensional deformity of the growing spine, affecting $2 \%-3 \%$ of adolescents. Although benign in the majority of patients, the natural course of the disease may result in significant disturbance of body morphology, reduced thoracic volume, impaired respiration, increased rates of back pain, and serious esthetic concerns. Risk of deterioration is highest during the pubertal growth spurt and increases the risk of pathologic spinal curvature, increasing angular value, trunk imbalance, and thoracic deformity. Early clinical detection of scoliosis relies on careful examination of trunk shape and is subject to screening programs in some regions. Treatment options are physiotherapy, corrective bracing, or surgery for mild, moderate, or severe scoliosis, respectively, with both the actual degree of deformity and prognosis being taken into account. Physiotherapy used in mild idiopathic scoliosis comprises general training of the trunk musculature and physical capacity, while specific physiotherapeutic techniques aim to address the spinal curvature itself, attempting to achieve self-correction with active trunk movements developed in a three-dimensional space by an instructed adolescent under visual and proprioceptive control. Moderate but progressive idiopathic scoliosis in skeletally immature adolescents can be successfully halted using a corrective brace which has to be worn full time for several months or until skeletal maturity, and is able to prevent more severe deformity and avoid the need for surgical treatment. Surgery is the treatment of choice for severe idiopathic scoliosis which is rapidly progressive, with early onset, late diagnosis, and neglected or failed conservative treatment. The psychologic impact of idiopathic scoliosis, a chronic disease occurring in the psychologically fragile period of adolescence, is important because of its body distorting character and the onerous treatment required, either conservative or surgical. Optimal management of idiopathic scoliosis requires cooperation within a professional team which includes the entire therapeutic spectrum, extending from simple watchful observation of nonprogressive mild deformities through to early surgery for rapidly deteriorating curvature. Probably most demanding is adequate management with regard to the individual course of the disease in a given patient, while avoiding overtreatment or undertreatment.

Keywords: management, idiopathic scoliosis, adolescence

\section{Detection and screening of idiopathic scoliosis}

In patients with idiopathic scoliosis, skeletal deformity results in visible external abnormalities, including lateral deviation of the spinous processes, asymmetry of the shoulders, scapulae, waistline, and/or hips, lateral imbalance of the trunk, humps in the rib cage or lumbar region, and disturbances in physiologic kyphosis and lordosis. ${ }^{1,2}$ These signs are very likely to go unnoticed at the early stage of idiopathic scoliosis ${ }^{3-5}$ (Figure 1). 

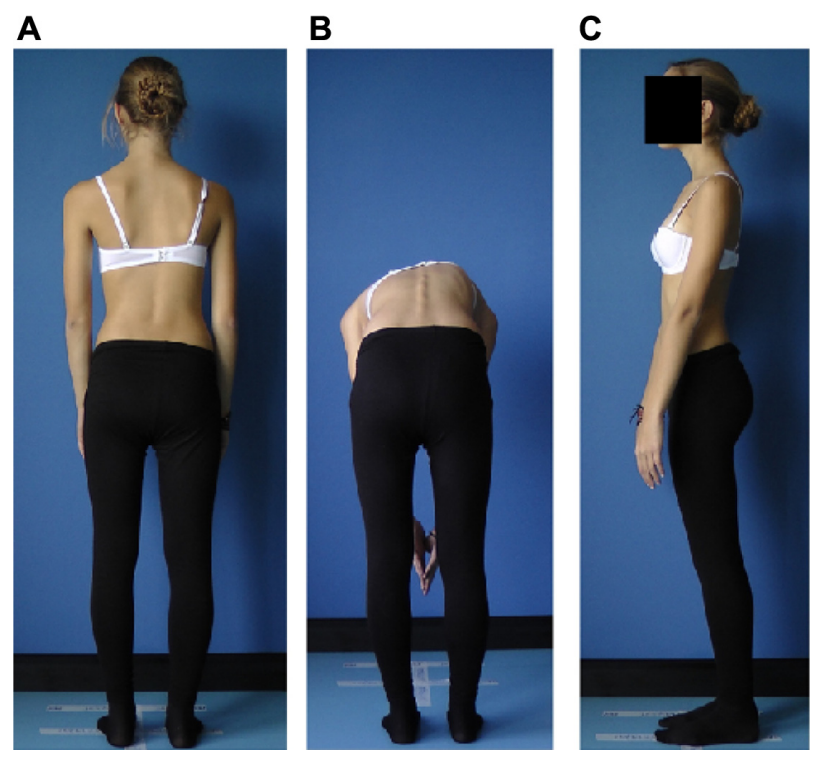

Figure I Clinical signs of idiopathic scoliosis. (A) Trunk asymmetry and lateral deviation of the spine in the frontal plane, (B) trunk rotation in the horizontal plane, and $(\mathbf{C})$ disturbances in physiological curvature in the sagittal plane (kyphosis flattening).

School-based screening for scoliosis is performed primarily for the purpose of early detection of spinal deformity, which enables implementation of early conservative treatment that can reduce the risk of curve progression..$^{3,6-14}$ The screening test should have high sensitivity and specificity, although it is not intended to be diagnostic. ${ }^{15,16}$ Suspicion of idiopathic scoliosis in adolescence is based on detection of three-dimensional deformity of the spine and trunk occurring for unknown reasons in a healthy adolescent between the age of 10 years and skeletal maturity. ${ }^{1,12}$ Confirmation of the diagnosis is based on radiographic examination of the spine revealing its deformity, where the magnitude of curvature in the frontal plane has a Cobb angle greater than $10^{\circ}$. Although X-ray is the gold standard for diagnosis of idiopathic scoliosis, it is not used as a screening method because of the risks associated with radiation exposure. ${ }^{1,2}$

Prediction of the course of infantile scoliosis is done based on Mehta's rib-vertebra relationship as studied on the anteroposterior radiogram. ${ }^{17}$ Increased downward obliquity of the ribs on the convex side, an apical rib shadow overlapping the corresponding vertebral body, or a rib-vertebra angle difference of $\geq 20^{\circ}$ indicate progressive scoliosis. . $^{17,18}$ Recent studies have shown that measurement of the ribvertebra angle difference can also be used as a prognostic factor in juvenile scoliosis. ${ }^{18,19}$ Magnetic resonance imaging is indicated in the presence of unusual findings (eg, an uncommon curvature pattern, pain, trunk stiffness) to search for other conditions, such as spondylolisthesis, tumors, tethered spinal cord, or syringomyelia. ${ }^{1}$ Generally, idiopathic scoliosis is not associated with neurologic deficits nor pain.

To be effective, a scoliosis screening program should meet the following requirements: it should rely on noninvasive tests that can detect early changes; be acceptable to the population; be simple, rapid, and inexpensive to perform; and the cost of case finding should be economically balanced in relation to total medical care expenditure. Moreover, it requires evidence of effective intervention and availability of facilities for diagnosis and treatment. ${ }^{15,16}$

Several techniques have been developed for early detection of scoliosis. Basic visual postural assessment can be performed in 30 seconds. ${ }^{5,20}$ This is based on inspection of the trunk from the front, side, and back while the child is standing in a natural position and in the forward-bending position (Adams test) in order to identify the presence of a rib hump. ${ }^{5,20}$ According to the World Health Organization, two factors contribute to the reliability of a screening test, ie, variation of the method and variation of the observer. ${ }^{15}$ Accuracy of visual assessment depends on the experience and skills of the screener. ${ }^{21}$ Côté et a ${ }^{22}$ reported that the Adams forward-bending test is $92 \%$ sensitive and $60 \%$ specific in detection of thoracic curves with a Cobb angle $\geq 20^{\circ}$. For detection of lumbar curves, the Adams test is $73 \%$ sensitive and $68 \%$ specific. Côté et al also reported an interexaminer reliability coefficient of 0.61 for detection of thoracic rotational prominence and 0.29 for lumbar prominence.

The Bunnell scoliometer, a specially designed inclinometer, was introduced in 1984 to limit the subjectivity of the forward-bending test. ${ }^{23}$ It is used for fast and easy quantitative determination of the degree of trunk rotation. ${ }^{3,6,23}$ The angle of trunk rotation should be measured at three levels of the spine, ie, proximal thoracic, main thoracic, and thoracolumbar or lumbar. ${ }^{23}$ Measurement of the angle of trunk rotation by scoliometer is reported to have interobserver and intraobserver reliability of $\pm 2.0^{\circ}$ to $\pm 4.0^{\circ} .^{24,25}$

In response to criticism by the US Preventive Services Task Force, Bunnell went to a minimum $7^{\circ}$ angle of trunk rotation as a criterion for referral, from a previously recommended angle of $5^{\circ}$, to decrease the number of false positives. ${ }^{23,26}$ This increased criterion results in a referral rate of about $3 \%$, corresponding to the prevalence of scoliosis in the general population. ${ }^{1,26-32}$ According to Bunnell, $95 \%$ of curvatures $\geq 30^{\circ}$ would be detected, while $12 \%$ of $20^{\circ}$ curvatures would be missed. However, it is also recommended that children with a lower degree of trunk deformity $\left(4^{\circ}-6^{\circ}\right.$ trunk rotation), which can indicate the presence of mild scoliosis, 
should be rescreened in 4-12 months..$^{23,24}$ Ashworth et $\mathrm{al}^{33}$ report that the cutoff value for an angle of trunk rotation $\geq 7^{\circ}$ is characterized by high sensitivity $(83.3 \%)$ and high specificity $(86.8 \%)$. Rotational deformity of the thorax can also be measured using other devices, eg, a spirit level or ruler, ${ }^{23}$ the spinal rotation meter introduced by Pruijs, ${ }^{24,34}$ or a regular smartphone with an acrylic sleeve. ${ }^{35}$

Axial rotation of the vertebrae is only one aspect of the three-dimensional nature of scoliotic deformity. Amendt et al ${ }^{36}$ correlated two radiographic parameters, ie, pedicle rotation and Cobb angle, and obtained coefficients ranging from 0.48 to 0.70 . These investigators also assessed agreement between the angle of trunk rotation on the scoliometer and radiographic pedicle rotation measurements, and found a poor correlation of $0.32-0.46 .{ }^{36}$ The relationship between spinal curvature (radiographic Cobb angle) and the surface (angle of trunk rotation) shows a significant correlation of $0.46-0.89$, but the standard deviation is high. ${ }^{3,23,30,36}$ Bunnell ${ }^{23}$ states that it is not possible to predict the degree of curvature from surface topography reliably in any given patient or by any given technique. Visible surface asymmetry involves many structures, including the spine, rib cage, muscles, viscera, fat, and skin, that are unique to each patient and change over time with progression of deformity. Grivas et $\mathrm{a}^{37}$ showed that the correlation between surface and radiologic deformity is weak in younger children (aged $7-13$ years) but becomes stronger in older children (aged 14-18 years).

Surface topography is another method which is popular for both screening and follow-up. ${ }^{3,38-40}$ Surface topography is based on evaluation of external body contour and can be performed using several techniques. Moire topography was the first photogrammetric method, introduced in 1970 by Takasaki. ${ }^{41,42}$ Nowadays, raster stereography and light beam body scanning are the most commonly used. ${ }^{39,40,43}$ While surface topography methods enable accurate, noninvasive, three-dimensional assessment of trunk shape, the time and expense required to perform these studies make them impractical for mass screening. ${ }^{3,23,40}$ Surface topography equipment requires delivery, adaptation to space and access to a computer. Surface topography examination is more complex than inclinometry and requires longer training of personnel. Using surface topography, there is a need to uncover the whole surface of the back, which prolongs the preparation time and can be problematic for adolescent girls in a school environment. Further, more research on surface topography is needed because of the lack of specific referral criteria regarding parameters and cutoff values. ${ }^{40}$
Despite the often voiced concern about excessive costs and over-referral, screening programs have been shown to be cost-effective when screeners are well trained and appropriate referrals are made to minimize the lack of specificity. ${ }^{3,6,11}$ It has been suggested that its effectiveness may be further improved by targeted screening of high-risk groups according to age and gender., ${ }^{3,4}$ The ratio of girls to boys with small curves is similar, but scoliosis in girls tends to progress more often. ${ }^{1,24,32}$ The Scoliosis Research Society, American Academy of Orthopedic Surgeons, Pediatric Orthopedic Society of North America, and American Academy of Pediatrics statements recommend that school-based programs screen girls for scoliosis twice at ages 10 and 12 years and boys once at age 13 or 14 years. ${ }^{2}$

Grivas et $\mathrm{a}^{44}$ showed that geographical latitude has an influence on the prevalence of idiopathic scoliosis and age at menarche in girls. Because future growth potential and magnitude of the curve at the time of diagnosis are important determinants of progression of idiopathic scoliosis, it is considered that girls who live in countries further north than 25 degrees should be screened at an older age than those living south of this latitude. ${ }^{3,44}$

Suggestions for more efficient screening also consider the use of a sitting forward-bending position which provides more stable posture and shows the real trunk asymmetry, that is revealed due to leveling of the pelvis and elimination of any effect of unequal leg length on shape of the back. ${ }^{3,24,45}$ Grivas et $\mathrm{al}^{24}$ and Chowanska et $\mathrm{al}^{46}$ report that the sitting position demonstrates a better surface-spinal deformity correlation than the standing position.

In order to achieve reasonable direct and indirect costeffectiveness of screening programs, overexposure to X-rays and overtreatment must be avoided. ${ }^{3}$ Not all children referred because of a positive screening result require radiography and treatment. Moreover, children with equivocal findings should remain under the observation of a school nurse, and only those with more severe findings should be referred to a physician. ${ }^{3,5,16,23}$ The National Scoliosis Foundation ${ }^{5,20}$ recommends two-stage screening to increase the efficiency and effectiveness of detection. The first stage is focused on getting the true negative cases back to their classes and the second stage concentrates on confirming the true positive cases.

\section{Role of physiotherapy General considerations}

Physiotherapy is one of the components of conservative treatment in children with idiopathic scoliosis. ${ }^{12,47,48}$ It can be applied in the form of exercises or sometimes as physical 
therapy involving electrostimulation of the paravertebral muscles. ${ }^{12,47,48}$ Opinions as to the efficacy of physiotherapy for idiopathic scoliosis differ. ${ }^{48-50}$ On the one hand, there is a lack of adequate scientific data confirming the effectiveness of physiotherapy in reducing the risk of progression of scoliosis; ${ }^{48,49}$ on the other, a number of publications indicate the positive influence of exercises on the course of scoliosis. ${ }^{12,48,49,50}$ Unfortunately, the majority of reviews show that the studies reported have an insufficient level of evidence, ${ }^{48-50}$ and the objective difficulties in organizing and conducting studies to obtain appropriate scientific evidence need to be borne in mind. ${ }^{48,50}$

Exercises for idiopathic scoliosis are based on various strategies of therapeutic management, and differ in terms of methodologic assumptions, duration of performance, the number of days a week they are done, and the way they are performed, ie, with a physiotherapist or individually. ${ }^{12,51-58}$

\section{Specific physiotherapeutic exercises}

To systematize exercises for idiopathic scoliosis, the Society on Scoliosis Orthopaedic and Rehabilitation Treatment (SOSORT) drew up a consensus document on physiotherapeutic management. ${ }^{12}$ The term "specific physiotherapeutic exercises" was defined according to evidence-based medicine guidelines. In order to recognize a particular physiotherapeutic method as being specific for idiopathic scoliosis, it has to demonstrate usefulness in treating children, adolescents, and adults with the condition, ie, an influence on the curvature angle, improvement in cardiorespiratory parameters, reduction or abolition of pain, and improvement in body esthetics and quality of life. ${ }^{12,47}$ Moreover, each method should comprise: three-dimensional correction of deformity with the focus on restoration of spinal curvature in the sagittal plane; stabilization of actively corrected body posture; and training of adolescents in how to maintain the corrected body posture while performing activities of daily living. . $2,47^{2}$

Education of children and parents involves explanation of the nature of the disease, together with its possible course and potential consequences, realistic therapeutic objectives, rules while performing physical (including home-based) exercises, and cooperation with the physiotherapist and physician supervising the treatment.

Specific physiotherapeutic exercises should be conducted by a trained and certified physiotherapist operating within a therapeutic team including a psychologist, orthotist, orthopedist, and a medical rehabilitation specialist. Cooperation with a school nurse, physical education teacher, and corrective gymnastics instructor is also needed. Specific physiotherapeutic exercise has to be adapted to the individual curvature pattern of the child and the treatment phase. Individually tailored therapy should be revised regularly and systematically. Objective documentation and verification of the results are crucial. ${ }^{12,47,59}$ There are several methods that can be used for specific physiotherapeutic exercises which meet the abovementioned criteria, ${ }^{12,60}$ ie, the Barcelona School, ${ }^{61}$ DoboMed, ${ }^{62}$ Functional Individual Therapy for Scoliosis, ${ }^{13}$ Lyon, ${ }^{63}$ Schroth, ${ }^{64}$ Scientific Exercises Approach To Scoliosis, ${ }^{65}$ and Side Shift ${ }^{66}$ techniques.

Patients should meet with the physiotherapist on 2-4 occasions each month, with exercises completed at home on an outpatient basis. The nearest medical center leading in a given method is usually consulted every 3-4 months to verify the quality of exercises and set new therapeutic objectives. ${ }^{12,47}$

It is worth emphasizing that specific physiotherapy can be helpful in supporting brace treatment and preparing the child for surgery. ${ }^{12,47,67}$ Physiotherapy can be modified and adapted to specific objectives, including: preparation for brace treatment by increasing spinal mobility and mobilizing soft tissues; ${ }^{12,52}$ increasing stability of the corrected body posture to reduce loss of correction after completion of brace treatment; ${ }^{12,68,78}$ increasing patient compliance with brace treatment; ${ }^{69}$ and reducing the pain and functional limitations associated with surgical fusion of the spine. ${ }^{70}$ Because idiopathic scoliosis is associated with various respiratory and physical capacity impairments, ${ }^{71-74}$ physiotherapy plays a vital role in improving cardiovascular parameters via symmetrical and asymmetrical breathing exercises. ${ }^{12,75-77}$

Another physiotherapeutic technique, ie, inpatient rehabilitation, is practiced in selected European countries on an inpatient basis. It is started at the beginning of treatment to help educate the child and parents, usually lasts 3-4 weeks, and can be repeated at 6-12-month intervals. It is essential to supplement specific inpatient rehabilitation with outpatient therapy. ${ }^{12,47}$ Its effectiveness depends on the child's willingness to cooperate and parental involvement, as well as on the model of physiotherapeutic management selected. . $^{12,47}$

\section{Effectiveness of physiotherapy}

Studies of the usefulness of exercises ${ }^{48,50}$ indicate potential advantages resulting from therapy, including: reduction in Cobb angle, ${ }^{51,52,55,78,79}$ reduction in risk of progression in comparison with the natural history of idiopathic scoliosis, ${ }^{54,64,80}$ improvement in clinical parameters, ie, lateral deviation, surface rotation, ${ }^{81}$ and angle of trunk rotation,,${ }^{55,72}$ improved 
body esthetics, ${ }^{55}$ fewer patients requiring brace treatment, ${ }^{55,78}$ and fewer patients requiring surgical treatment. ${ }^{82}$

Mordecai and Dabke ${ }^{48}$ analyzed 155 publications on the effectiveness of exercise. Only 12 of these papers met their inclusion criteria, ie, treatment involving only exercise, at least level IV evidence, ${ }^{48,83}$ at least one month of follow-up, and a minimum of one defined outcome measure. Nine of the 12 papers were identified as prospective cohort studies, of which three were controlled and only one had observer blinding. The authors indicated that the inclusion criteria, recommendations, and contraindications to exercise were not clearly determined in any of these papers. Cobb angle was the basic parameter taken into consideration, ${ }^{51,52,66,78,82,84}$ and any changes in its magnitude were usually statistically significant. However, the size of these changes was small, ${ }^{85,86}$ often within the range of measurement error for Cobb angle $\left(1.7^{\circ}-6.5^{\circ}\right)$. Negrini et $\mathrm{al}^{78}$ found that the Cobb angle decreased by $0.67^{\circ}$ in 35 patients treated with Scientific Exercises Approach To Scoliosis physiotherapy, in contrast with an increase of $1.38^{\circ}$ in the group treated with nonspecific physiotherapy. Otman et $\mathrm{al}^{51}$ observed a reduction in mean Cobb angle from $26.1^{\circ}$ to $17.8^{\circ}$ in a group of 50 patients performing exercises five days a week, four hours a day, for six weeks under therapist supervision and followed with exercises performed at home for a year. Weiss et a ${ }^{84}$ noted an increase in mean Cobb angle from $27^{\circ}$ to $29^{\circ}$ after 33 months in 181 patients treated with the Schroth method. An increase in Cobb angle of $\geq 6^{\circ}$ was observed in $25 \%$ of patients and a decrease of $\geq 6^{\circ}$ in $18 \%$ of patients. The authors concluded that there was a positive outcome when compared with the natural history of scoliosis, which has a natural progression rate of $62 \%$.

\section{Scoliosis and sport}

Physiotherapy for scoliosis encompassing sporting activity has a significant influence on enhancing physical fitness, increasing body awareness, and improving self-esteem and quality of life..$^{12,76,77,87}$ Children with idiopathic scoliosis may participate actively in physical education classes. After surgical treatment, a gradual return to sport activity takes up to one year with possible exclusion of sports requiring full flexibility of the spine. The patients return to noncontact sports six months after surgery, while contact sports are usually allowed one year after surgery. ${ }^{88}$

\section{Conservative treatment with corrective bracing}

The aims of conservative treatment of idiopathic scoliosis according to the SOSORT 2011 consensus document are to stop curve progression, to prevent respiratory dysfunction, to prevent or treat back pain, and to improve esthetics. ${ }^{12}$

\section{Indication for bracing}

Brace treatment is recommended for skeletally immature adolescents with idiopathic scoliosis and a Cobb angle of $25^{\circ}-40^{\circ}$. Nevertheless, each clinical situation should be evaluated, and for each patient, a maximum and minimum treatment can be assessed according to the practical approach recommended in the 2011 SOSORT consensus document (Table 1). ${ }^{12}$ Therapeutic decisions beyond the maximum or minimum indicate overtreatment (too much burden on the patient) or undertreatment (not enough efficacy), respectively. ${ }^{12}$

When using the practical approach, it is helpful to consider prognostic factors in order to chose an optimal option between maximum and minimum treatment. ${ }^{12}$ Bunnell reported that the risk of progression at the onset of puberty is $20 \%$ in $10^{\circ}$ scoliosis and $90 \%$ in $30^{\circ}$ scoliosis, and decreases during the final stage of puberty to $2 \%$ in $10^{\circ}$ scoliosis, $20 \%$ in $20^{\circ}$ scoliosis, and $30 \%$ in $30^{\circ}$ scoliosis. ${ }^{89}$ The prognostic formula proposed by Lonstein and Carlson takes into account chronological age, Cobb angle, and the Risser sign. ${ }^{90}$ The following factors have been suggested as possible determinants of an increased risk for progression of scoliosis: positive family history, laxity of skin and joints (connective tissue defect), flattening of thoracic kyphosis, ${ }^{91}$ angle of trunk rotation exceeding $10^{\circ}$, and growth spurt. ${ }^{89}$ Other factors associated with a higher risk of curve progression are trunk imbalance and a short curve. The esthetic impact is also important in making a decision about brace treatment. ${ }^{12,92}$

The potential genetic contribution to idiopathic scoliosis has been studied in over 60 publications, with over 30 candidate genes and 18 unique loci suggested..$^{93} \mathrm{~A}$ genetic prognostic test has recently been proposed, based on the presence of 53 single nucleotide polymorphisms. ${ }^{94}$ Although initial results have been promising, further research seems necessary. ${ }^{12}$ Genetic assessment of the risk of progression in young patients with newly diagnosed idiopathic scoliosis can potentially reveal cases with a poor prognosis. On the other hand, it could help in avoiding overtreatment in cases of nonprogressive scoliosis.

\section{Main types of braces}

Braces can be classified according to construction (rigid brace or soft brace), wearing time (full-time $100 \%$, part-time $50 \%$, night-time $30 \%$ ) as well as suitability to location of the main scoliotic curvature (cervical, thoracic, lumbar, sacral). ${ }^{95}$ The 
success of brace treatment in progressive idiopathic scoliosis is usually defined as the rate of patients with progression not exceeding $6^{\circ}$ of Cobb angle.

The Cheneau brace is a rigid polyethylene orthotic device invented by Jacques Cheneau in 1972. It is a TLSO (thoraco-lumbo-sacral orthosis) type of brace designed mainly for thoracic, low thoracic, thoracolumbar, or lumbar scoliosis. Double-curve and triple-curve scoliosis can also be treated well using this brace, but not cervicothoracic scoliosis. The Cheneau brace acts by a combination of passive and active mechanisms of correction. The passive mechanisms comprise three-dimensional tissue transfer, an elongation effect, derotation of the rib cage, and bending. The active mechanisms comprise guidance of vertebral growth, asymmetrically guided respiratory movements, repositioning of the arrangement of trunk muscles, and an antigravitational effect. ${ }^{96}$ The success of treatment (progression below $6^{\circ}$ ) is achieved in $48.1 \%-85.7 \%$ of patients. ${ }^{97,98}$ Boston, Gensingen, Lapadula, Lyonese, Progressive Action Short Brace, Sforzesco, Sibilla are other examples of rigid TLSOs. ${ }^{99-102}$

The SpineCor is a soft brace devised in the 1990s by Rivard and Coillard. It comprises a pelvic unit and a system of elastic bands which wrap around the body in a specific pattern adapted to the curvature pattern. The idea of the SpineCor is to introduce specific corrective movement dependent on the type of the curve.
It is postulated that full-time corrective movement helps to achieve neuromuscular integration and avoid loss of correction after weaning from the brace. A success rate of 59.4\%-68.0\% has been reported. ${ }^{103-105}$ The TriaC, Olympe, Spinealite, and St Etienne are other examples of soft braces. ${ }^{106,107}$

Night-time rigid braces are being worn during sleep (6-10 hours per day). The Charleston brace is a plastic orthotic device developed by Reed and Hooper in 1978, which keeps the spine in overcorrection by application of direct, lateral, and rotational forces on the trunk to move the spine toward the midline or beyond the midline. ${ }^{99,108}$ The success rate using this treatment is reported in the range of $12 \%-66 \% .{ }^{109,110}$ The Providence brace is another example of a night-time rigid brace..$^{99}$

The Milwaukee brace is a CTLSO (cervico-thoracolumbo-sacral orthosis) orthotic device was constructed by Blount and Moe in 1945 and is still in use. The brace consist of a pelvic girdle and a neck ring connected with two posterior and one anterior metal rods. ${ }^{99,111}$ It works by applying longitudinal forces completed with lateral forces. Some correction by active autoelongation is also observed. The brace can be used to correct single, double, and triple curves variously situated, including in the cervicothoracic location. ${ }^{12}$ The results are reported to have a success rate of $52.0 \%-77.0 \%$ for avoiding progression of the curve. ${ }^{113,114}$

Table I Practical approach for adolescent idiopathic scoliosis according to the Society on Scoliosis Orthopaedic and Rehabilitation Treatment 201 I consensus document

\begin{tabular}{|c|c|c|c|c|c|c|c|c|c|c|}
\hline & \multicolumn{10}{|c|}{ Cobb angle } \\
\hline & $\begin{array}{l}0-10^{\circ}+ \\
\text { hump }\end{array}$ & $11^{\circ}-15^{\circ}$ & $16^{\circ}-20^{\circ}$ & $21^{\circ}-25^{\circ}$ & $26^{\circ}-30^{\circ}$ & $31^{\circ}-35^{\circ}$ & $36^{\circ}-40^{\circ}$ & $41^{\circ}-45^{\circ}$ & $46^{\circ}-50^{\circ}$ & $>50^{\circ}$ \\
\hline \multicolumn{11}{|c|}{ Risser 0} \\
\hline Min & Ob 6 & Ob 6 & Ob 3 & PSE & PSE & SSB & PTRB & PTRB & PTRB & FTRB \\
\hline Max & Ob 3 & PSE & PTRB & FTRB & FTRB & FTRB & FTRB & FTRB & $\mathrm{Su}$ & $\mathrm{Su}$ \\
\hline \multicolumn{11}{|c|}{ Risser I } \\
\hline Min & Ob 6 & Ob 6 & Ob 3 & PSE & PSE & SSB & PTRB & PTRB & PTRB & FTRB \\
\hline Max & Ob 3 & PSE & PTRB & FTRB & FTRB & FTRB & FTRB & FTRB & $\mathrm{Su}$ & Su \\
\hline \multicolumn{11}{|c|}{ Risser 2} \\
\hline Min & Ob 8 & Ob 6 & Ob 3 & PSE & PSE & SSB & SSB & SSB & SSB & FTRB \\
\hline Max & Ob 6 & PSE & PTRB & FTRB & FTRB & FTRB & FTRB & FTRB & Su & Su \\
\hline \multicolumn{11}{|c|}{ Risser 3} \\
\hline Min & Ob 12 & Ob 6 & Ob 6 & Ob 6 & PSE & SSB & SSB & SSB & SSB & FTRB \\
\hline Max & Ob 6 & PSE & PTRB & FTRB & FTRB & FTRB & FTRB & FTRB & $\mathrm{Su}$ & Su \\
\hline \multicolumn{11}{|c|}{ Risser 4} \\
\hline Min & No & Ob 6 & Ob 6 & Ob 6 & Ob 6 & Ob 6 & Ob 6 & Ob 6 & SSB & FTRB \\
\hline $\operatorname{Max}$ & Ob 12 & PSE & PTRB & FTRB & FTRB & FTRB & FTRB & FTRB & $\mathrm{Su}$ & $\mathrm{Su}$ \\
\hline \multicolumn{11}{|c|}{ Risser 4-5 } \\
\hline Min & No & Ob 6 & Ob 6 & Ob 6 & Ob 6 & Ob 6 & Ob 6 & Ob 6 & SSB & FTRB \\
\hline $\operatorname{Max}$ & Ob 12 & PSE & PTRB & FTRB & FTRB & FTRB & FTRB & FTRB & Su & Su \\
\hline
\end{tabular}

Note: Adapted from Negrini S, Aulisa AG, Aulisa L, et al. 201 I SOSORT guidelines: Orthopaedic and rehabilitation treatment of idiopathic scoliosis during growth. Scoliosis. 2012;7:3.12

Abbreviations: Ob, observation every I2/8/6/4 months; PSE, specific physiotherapeutic exercises; SSB, soft bracing; PTRB, part-time rigid bracing (I2-20 hours); FTRB, full-time rigid bracing (20-24 hours) or cast; Su, surgery; Min, minimum; Max, maximum. 
It should be emphasized that direct comparison of the reported results of treatment is difficult because of the divergent methodology used for assessment. The TLSO is more comfortable for the patient to wear and easier to hide under the clothes than the CTLSO. However, only the CTLSO can be used for high thoracic and cervicothoracic scoliosis. ${ }^{99}$ Generally, soft braces are claimed to be more comfortable to wear than rigid braces, but a study by Wong et al ${ }^{105}$ and our clinical experience do not confirm this suggestion.

\section{Effectiveness of brace treatment}

Evidence for the effectiveness of bracing for idiopathic scoliosis in most studies is of very low quality, and the methods used for evaluation are not consistent. Studies of brace treatment are difficult to compare, and many additional factors could have influenced on their results. It is not possible at this time to state with any certainty which brace is more effective than another. ${ }^{12}$

Negrini et al have published a Cochrane review on brace treatment for idiopathic scoliosis. Their criteria were randomized controlled trials and prospective cohort studies comparing braces with no treatment, other treatment, surgery, and different types of braces. They identified 1285 titles, from which 128 full texts were reviewed. ${ }^{115}$ Only two studies met their inclusion criteria, ie, one by Wong et al in $2008^{105}$ and the other by Nachemson et al in $1995 .{ }^{116}$ The conclusions of the reviewers were that there is very limited quality evidence that braces are more effective than observation or electrical stimulation, and there is lowquality evidence that rigid braces are more effective than soft braces. ${ }^{115}$

Wong et al performed a randomized controlled trial comparing the effectiveness of treatment and patient acceptance of the SpineCor soft brace $(\mathrm{n}=22)$ versus a rigid brace $(\mathrm{n}=21)$ in skeletally immature patients with idiopathic scoliosis and a Cobb angle of $20^{\circ}-30^{\circ}$. They reported a success rate of $68 \%$ for patients in the soft brace group and $95 \%$ in the rigid brace group. There was no significant difference between the groups in subjective perception of daily difficulties associated with wearing the brace. ${ }^{105}$

Nachemson et al performed a prospective international multicenter study in 240 girls with scoliosis of $20^{\circ}-35^{\circ}$. In total, 111 girls were treated with a rigid brace for at least 16 hours per day, 129 were observed, and 46 underwent night-time electrical surface stimulation of paravertebral muscles. The reported success of the treatment (curve progression $<6^{\circ}$ ) was $74 \%$ for rigid braces versus $34 \%$ for observation versus $33 \%$ for electrical stimulation. ${ }^{116}$
Rowe et al performed a meta-analysis comparing the success rate of different methods of treatment. The best results were achieved for braces worn for 23 hours daily. The most effective brace system was the Milwaukee brace. The Charleston brace was the least successful, but was still better than observation. ${ }^{117}$

Brace treatment should be performed by an experienced therapeutic team, including a physician, physiotherapist, orthotist, and psychologist. Support groups and Internet forums are helpful. ${ }^{69}$ It is important that both the patient and the caregivers participate actively in the course of treatment. Education, psychotherapy, systematic monitoring of outcome, assessment of patient cooperation and compliance, verification and modification of methods in the course of the therapy, and proper brace fit are crucial elements of successful treatment. ${ }^{69}$

\section{Place of surgery}

The main goals of operative treatment for progressive idiopathic scoliosis in the adolescent age group are to halt progression of deformity, to achieve three-dimensional correction of pathologic spinal curvature, to balance the trunk, to reduce the hump, to maintain permanent correction at longterm follow-up, and finally, to perform the demanding surgical procedure in the most safe conditions for the patient. ${ }^{119}$ However, surgery for idiopathic scoliosis does not restore the normal spine. Correction of scoliosis using spinal implants is completed systematically, with spinal fusion covering all the instrumented levels. ${ }^{118}$ Surgery for idiopathic scoliosis is advised if the Cobb angle exceeds a threshold of $50^{\circ}$ at completion of growth and even more when a risk of progression remains. ${ }^{12,118}$ Loss of physiologic sagittal curvatures may be an additional argument in favor of surgery because a harmonious spinal profile is considered one of the important determinants of being free of back pain in adulthood. ${ }^{118,119}$ The esthetic aspect is of great importance. The final decision regarding operative treatment for idiopathic scoliosis should be an intentional choice made by the patient and parents supplied with adequate information about the surgery itself and the postsurgical course. For example, limitation in sport and physical activities is related to extension of spinal fusion, but for a typical single thoracic curvature, this is barely noticeable by the patient.

The rate of surgery after brace treatment has been reported to range from $11 \%$ to $42.5 \%{ }^{120,121}$ For children previously managed conservatively, need for surgery may be perceived as failure rather than continuation of treatment. On the other hand, many adolescents refuse conservative treatment from 
the outset and readily accept the surgical option. Still others will need psychologic support to accept surgery and improve motivation.

Preparing the patient for surgery requires a thorough clinical and radiologic evaluation. Measurements of Cobb angle for the major and minor curves are taken from a standing frontal long-cassette radiograph. ${ }^{122,123}$ The tilt of the inferior limit vertebrae and of the stable vertebrae measured to the horizontal line, apical vertebra translation to the central sacral vertical line, as well as global coronal balance by relating $\mathrm{C} 7$ to the central sacral vertical line are assessed. Vertebral rotation is measured using the Perdriolle or Nash-Moe method. ${ }^{124,125}$ Curve flexibility is determined on supine bending X-rays and traction film. Global sagittal balance is assessed on the lateral standing projection considering the distance from the $\mathrm{C} 7$ plumb line to the first sacral vertebral body, and thoracic kyphosis and lumbar lordosis are evaluated. ${ }^{126}$

On the basis of radiologic measurement, the curves are classified using the method described by Lenke et al. ${ }^{127}$ The type of curve implies extent of instrumentation, ie, indicates structural curves requiring fusion, whereas nonstructural regions will not be fused. ${ }^{128,129}$ Sparing spinal levels from surgical fusion is always one of the goals of preoperative planning, especially at the lumbar spine. The recommendations made by Lenke et al for fusion are described in Table 2. ${ }^{28}$

In recent years, there has been significant progress in the surgical treatment of scoliosis, in terms of progress in construction of spinal implants and instruments, and in safety of the procedures by use of blood salvage techniques and intraoperative neurophysiologic monitoring of the spinal cord. $^{118}$

Posterior spinal instrumentation is the most widely used technique in the surgical treatment of idiopathic scoliosis (Figure 2). Milestones in this approach are represented by the techniques devised by Harrington in 1962 and CotrelDubousset in 1984. ${ }^{130,131}$ Posterior instrumentation provides good curve correction in three dimensions, reduces rib prominence, tends to reduce the number of fused vertebral levels, and avoids the need for a postoperative brace. Curve correction is achieved using screws, hooks, or wires carefully implanted in previously exposed posterior elements of the vertebrae and connected with rods and transverse devices to form a stable framework. ${ }^{118}$ Corrective maneuvers for realignment of segmental vertebrae using a variety of techniques such as rod rotation, apex translation, distraction, and direct vertebral derotation, can be implemented. ${ }^{126}$ Solid bony fusion is achieved by meticulous posterior decortication and bone autograft (local, iliac, or costal) or by biological bone substitutes. ${ }^{118}$ Posterior spinal instrumentation is implanted through a vertical posterior midline skin incision.

Anterior instrumentation is an alternative to the posterior approach, using vertebral bodies to insert anchors and interbody fusion for stable correction. Anterior instrumentation is recommended mainly for single thoracolumbar and lumbar curves, providing good three-dimensional correction with a reduced number of fused levels. ${ }^{18,132}$ Anterior spinal instrumentation is implanted through an oblique lateral skin incision on the flank, leaving no scar on the back.

A number of studies have been published comparing different variants of instrumentation. Yilmaz et al reviewed 105 patients and showed that pedicle screws and hybrid (screw and hook) instrumentation give better correction of deformity, maintain this correction in the coronal and sagittal planes, and provide better patient satisfaction compared with hook-only constructs. ${ }^{126}$ Lilienquist et al came to similar conclusions based on an analysis of 95 patients. ${ }^{133} \mathrm{Kim}$ et al reported on 58 patients and noted that pedicle screw instrumentation achieved significantly improved correction of deformity and better postoperative pulmonary function than hybrid constructs. Both instrumentation methods provided similar junctional change, reduction in the number of fused levels, and decreased operative time. ${ }^{134,135}$ Cheng et al reported that use of apical sublaminar wires and pedicle screw instrumentation provided similar correction of deformity and comparable fusion lengths without neurologic problems. ${ }^{136}$ Cheng et al reported pedicle screws to be more expensive, but were associated with less blood loss than sublaminar wire constructs. ${ }^{136}$ The reported disadvantages of pedicle screws are its increased cost, steep learning curve, and safety concerns. ${ }^{118}$ Generally, it appears that any type of modern segmental spinal instrumentation offers similar correction capabilities. It seems justified to leave the choice of implant system to the surgeon who will rightly propose the system

Table 2 Treatment options implied by curve type according to the Lenke classification

\begin{tabular}{lll}
\hline Curve type & $\begin{array}{l}\text { Structural regions } \\
\text { recommended for fusion }\end{array}$ & Approach \\
\hline Main thoracic & MT & PSF or ASF \\
Double thoracic & PT, MT & PSF \\
Double major & MT-TL/L & PSF \\
Triple major & PT, MT, TL/L & PSF \\
Thoracolumbar/lumbar & TL/L & ASF or PSF \\
Thoracolumbar/lumbar, & TL/L, MT & PSF \\
main thoracic & & \\
\hline
\end{tabular}

Abbreviations: ASF, anterior spinal fusion; PSF, posterior spinal fusion; PT, proximal thoracic; MT, main thoracic; TL/L, thoracolumbar/lumbar. 


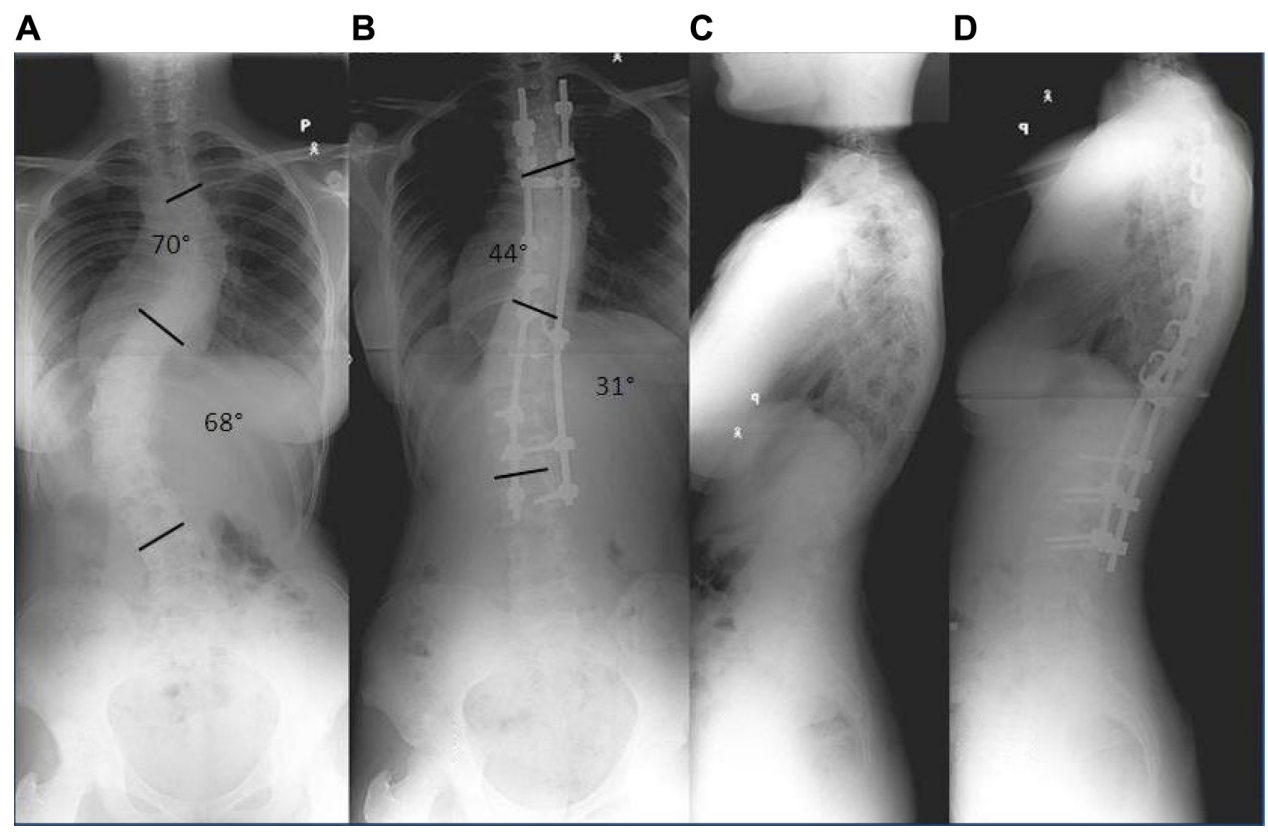

Figure 2 Surgical treatment of idiopathic scoliosis using posterior instrumentation. (A and C) Preoperative anteroposterior and lateral standing radiographs of an adolescent girl with progressive idiopathic scoliosis Lenke type 6CN. (B and D) Postoperative standing radiograph of the patient after hybrid-type posterior instrumentation. Satisfactory correction, increased trunk height, and a well balanced spine are seen in both the sagittal and coronal planes.

he or she is most familiar with. Modern instrumentation techniques no longer require postoperative cast or brace immobilization.

Rib hump is a cosmetic concern and one of the most frequent complaints reported by patients with idiopathic scoliosis. Application of new techniques and instrumentation systems has reduced the need for thoracoplasty. ${ }^{137}$ This procedure consists of resection of the ribs on the convex side or rib osteotomies on the concave side. ${ }^{138}$ Chen et al reported that thoracoplasty combined with posterior instrumentation resulted in a temporary decrease in vital capacity, which returned to preoperative values by one-year follow-up. ${ }^{139}$

\section{Psychologic aspects}

Quality of life in adolescents with idiopathic scoliosis is being increasingly recognized by physicians, physiotherapists, and other specialists, including psychologists and nurses. Analysis of the goals of treatment outlined in the SOSORT consensus document highlights the importance of patient quality of life, esthetics, psychologic well-being, and disability. ${ }^{60}$

The Scoliosis Research Society questionnaire, a specific health-related quality of life instrument, is used before and after corrective surgery for scoliosis. This questionnaire, introduced in 1999 as the SRS-24, ${ }^{140}$ consists of 24 items divided into two sections, with the first section containing the domains of pain, general self-image, general function, and function-activity, ${ }^{141}$ and the second section, appropriate only for postsurgical patients, measuring postoperative self-image, function after surgery, and satisfaction with surgery. The SRS24 was modified to the SRS-23, ${ }^{142}$ then to the SRS-22, ${ }^{143}$ and finally to the SRS-22 refined (SRS-22r). ${ }^{144}$ The aim of these modifications was to improve its psychometric properties, thereby increasing the precision by which health-related quality of life can be assessed in patients with scoliosis or related spinal deformity from the age of 10 years through to adulthood. ${ }^{145}$ The SRS-22 has 22 items, canvassing function, pain, selfimage, and mental health domains, and a subtotal score. ${ }^{146}$ The SRS-22 is more versatile than the SRS-24 because patients with nonoperative and operative scoliosis and healthy control groups can complete all sections. ${ }^{147}$ The original version of the SRS-22 has undergone many transcultural adaptations, including Spanish, ${ }^{148,149}$ Japanese, ${ }^{150,151}$ Italian, ${ }^{152}$ Chinese, ${ }^{153}$ Dutch, ${ }^{154}$ Korean, ${ }^{155}$ Turkish, ${ }^{156}$ Polish, ${ }^{157}$ Norwegian, ${ }^{158}$ Swedish, ${ }^{159}$ and French Canadian versions. ${ }^{160}$ The SRS-22r, which is the most thoroughly validated version, has been translated into Greek, ${ }^{161}$ Japanese, ${ }^{162}$ Persian, ${ }^{163}$ Brazilian, ${ }^{164}$ Spanish, ${ }^{165}$ Italian, ${ }^{166}$ and Swedish. ${ }^{145}$ Ranging from two to seven questions in each domain of the SRS-24, in the SRS$22 \mathrm{r}$ there are five each in the function, pain, self-image, and mental-health domains, and two questions about satisfaction/ dissatisfaction with management. The number of responses possible for each question has been standardized to five. Scores vary from 1 to 5 , with 5 being the best health condition. The 
maximum score for a five-question domain is 25 , and the minimum is 5. For a two-question domain, the totals are 10 and 2 , respectively. ${ }^{146}$

Studies comparing adolescents with idiopathic scoliosis and healthy controls have shown that the SRS patient questionnaires are able to discriminate between patients from healthy controls, ${ }^{140,150}$ varying curvature severity, ${ }^{140,151}$ and satisfaction levels in patients who are treated surgically. ${ }^{146}$ In the past few years, an increasing number of questionnaires assessing quality of life in nonsurgically treated patients have been devised, including the Scoliosis Quality of Life Index, ${ }^{167}$ a simplified version of the SRS-22 known as the Quality of Life Profile for Spinal Deformities, ${ }^{168}$ the Pediatric Outcomes Data Collection Instrument, ${ }^{168}$ the Child Health Questionnaire, ${ }^{169}$ the Berner Questionnaire for Well Being, ${ }^{170}$ and the Brace Questionnaire. ${ }^{171}$

The Brace Questionnaire is an instrument for measuring quality of life in adolescents with scoliosis who are being treated conservatively with a corrective brace. The Brace Questionnaire consists of 34 Likert-scale items associated with eight domains, ie, general health perception, physical functioning, emotional functioning, self-esteem and aesthetics, vitality, school activity, bodily pain, and social functioning. This questionnaire is designed to be self-administered and to be developmentally appropriate for patients aged 9-18 years. The minimum score on this questionnaire is 20 and the maximum is 100 . Higher scores indicate better quality of life. A subscale score can be calculated for each of the eight domains by dividing the total score of each dimension by the number of its items. ${ }^{171}$ The Brace Questionnaire has recently been validated in Polish. ${ }^{172}$

Two questionnaires can estimate the stress induced by deformity, ie, the Bad Sobernheim Stress QuestionnaireDeformity, and that induced by treatment with a brace, ie, the Bad Sobernheim Stress Questionnaire-Brace. ${ }^{173}$

The Trunk Appearance Perception Scale and Spinal Appearance Questionnaire were created to assess the selfimage of patients with scoliosis. ${ }^{174,175}$ The Spinal Appearance Questionnaire was designed to measure patient perception of several aspects of the appearance a spinal deformity. ${ }^{174}$

Studies comparing assessment by adolescents with those by their parents ${ }^{176}$ reported that parents gave better scores than those given by the adolescents themselves. ${ }^{177}$ Further studies investigating reliability and validity with regard to transcultural adaptations of these questionnaires for patients not treated with surgery and differences in quality of life according to gender are needed. Further research is also needed with larger sample sizes, taking into account gender and control groups. Psychologic aspects of care in adolescents with idiopathic scoliosis cannot be overestimated.

\section{Summary}

Idiopathic scoliosis has traditionally been considered to be a dangerous and life-threatening condition. It is no more, at least in developed countries, considering the whole therapeutic spectrum available. Most of the cases that are detected early appear to be benign, moderate cases benefit from conservative management, and severe cases can be treated successfully with surgery.

Medicine is increasingly turning towards prevention rather than treatment of disease. In the absence of ability to prevent occurrence of scoliosis, the focus should be on early detection to prevent possible progression. ${ }^{3,6}$ For Bunnell, scoliosis screening is "vitally important, but we don't want to screen out a whole bunch of people who don't need medical attention because it's very costly. We're not looking for the cheapest way to screen - we're looking for a better quality outcome for our patients". 3

Optimal management of idiopathic scoliosis requires that the professional team covers the whole therapeutic spectrum, extending from simple watchful observation for mild nonprogressive deformities, using all nonsurgical options for moderate cases, through to early surgery for dangerous, rapidly progressive curvatures. Adequate management tailored to the individual course of the disease in a given patient is probably the most demanding aspect of the management of adolescents with idiopathic scoliosis.

\section{Disclosure}

The authors report no conflicts of interest in this work.

\section{References}

1. Reamy BV, Slakey JB. Adolescent idiopathic scoliosis: review and current concepts. Am Fam Physician. 2001;64:111-116.

2. srs.org [homepage on the Internet]. Adolescent idiopathic scoliosis. Available from: http://www.srs.org/professionals/conditions_and_treatment/ adolescent_idiopathic_scoliosis/index.htm. Accessed August 27, 2012.

3. Grivas TB, Wade MH, Negrini S, et al. SOSORT consensus paper: school screening for scoliosis. Where are we today? Scoliosis. 2007;2:17.

4. Thilagaratnam S. School-based screening for scoliosis: is it costeffective? Singapore Med J. 2007;48:1012-1017.

5. mass.gov [homepage on the Internet]. Massachusetts Department of Public Health. Training material, postural screening program. Available from: http://www.mass.gov/eohhs/docs/dph/comhealth/school/psmanual04. pdf. Revised 1996. Accessed August 22, 2012.

6. McCarthy RE. Prevention of the complications of scoliosis by early detection. Clin Orthop Relat Res. 1987;222:73-78.

7. Soucacos PN, Soucacos PK, Zacharis KC, Beris AE, Xenakis TA. Schoolscreening for scoliosis. A prospective epidemiological study in northwestern and central Greece. J Bone Joint Surg Am. 1997;79A:1498-1503. 
8. Maruyama T, Kitagawa T, Takeshita K, Mochizuki K, Nakamura K. Conservative treatment for adolescent idiopathic scoliosis: can it reduce the incidence of surgical treatment? Pediatr Rehabil. 2003;6: 215-219.

9. Rigo M, Reiter $\mathrm{CH}$, Weiss HR. Effect of conservative management on the prevalence of surgery in patients with adolescent idiopathic scoliosis. Pediatr Rehabil. 2003;6:209-214.

10. Weiss HR, Weiss G, Schaar HJ. Incidence of surgery in conservatively treated patients with scoliosis. Pediatr Rehabil. 2003;6:111-118.

11. Grivas TB, Vasiliadis ES, O'Brien JP. How to improve the effectiveness of school screening for idiopathic scoliosis. Stud Health Technol Inform. 2008;135:115-121.

12. Negrini S, Aulisa AG, Aulisa L, et al. 2011 SOSORT guidelines: Orthopaedic and rehabilitation treatment of idiopathic scoliosis during growth. Scoliosis. 2012;7:3.

13. Bialek M. Conservative treatment of idiopathic scoliosis according to FITS concept: presentation of the method and preliminary, short term radiological and clinical results based on SOSORT and SRS criteria Scoliosis. 2011;6:25.

14. Lonstein JE, Bjorklund S, Wanninger MH, Nelson RP. Voluntary school screening for scoliosis in Minnesota. J Bone Joint Surg Am. 1982;64:481-488

15. Wilson JMG, Jungner G. Principles and practice of screening for disease. WHO Chron. 1968;22:11-27.

16. Williams JI. Criteria for screening: are the effects predictable? Spine 1988;13:1178-1186

17. Mehta MH. The rib-vertebra angle in the early diagnosis between resolving and progressive infantile scoliosis. J Bone Joint Surg Br. 1972;54:230-243.

18. Modi HN, Suh SW, Song HR, Yang JH, Ting C, Hazra S. Drooping of apical convex rib-vertebral angle in adolescent idiopathic scoliosis of more than 40 degrees: a prognostic factor for progression. $J$ Spinal Disord Tech. 2009;22:367-371.

19. McAlindon RJ, Kruse RW. Measurement of rib vertebral angle difference. Intraobserver error and interobserver variation. Spine. 1997;22:198-199.

20. scoliosis.org [homepage on the Internet]. National Scoliosis Foundation. Catch the curve-scoliosis screening video for young people. Available from: https://sites.google.com/site/wwwscoliosisorgawareness/catchthe-curve. Accessed August 27, 2012.

21. Lee CF, Fong DYT, Cheung KMC, et al. Referral criteria for school scoliosis screening assessment and recommendations based on a large longitudinally followed cohort. Spine. 2010;35:E1492-E1498.

22. Côté P, Kreitz BG, Cassidy JD, Dzus AK, Martel J. A study of the diagnostic accuracy and reliability of the scoliometer and Adam's forward bend test. Spine. 1998;23:796-802.

23. Bunnell WP. An objective criterion for scoliosis screening. J Bone Joint Surg Am. 1984;66A:1381-1387.

24. Grivas TB, Vasiliadis ES, Koufopoulos G, Segos D, Triantafyllopoulos G, Mouzakis V. Study of trunk asymmetry in normal children and adolescents. Scoliosis. 2006;1:19.

25. Mubarak SJ, Wyatt MP, Leach J. Evaluation of the intra-examiner and inter-examiner reliability of the scoliometer in measuring trunk rotation. Presented at the 19th annual meeting of the Scoliosis Research Society, Orlando, FL; September 19-22, 1984.

26. Bunnell WP. Selective screening for scoliosis. Clin Orthop Relat Res. 2005;434:40-45.

27. Lonstein JE. Screening for spinal deformities in Minnesota schools. Clin Orthop Relat Res. 1977;126:33-42.

28. Fong DY, Lee CF, Cheung KM, et al. A meta-analysis of the clinical effectiveness of school scoliosis screening. Spine. 2010;35: 1061-1071.

29. Yawn BP, Yawn RA, Hodge D, et al. A population-based study of school scoliosis screening. JAMA. 1999;282:1427-1432.

30. Korovessis PG, Stamatakis MV. Prediction of scoliotic Cobb angle with the use of the scoliometer. Spine. 1996;21:1661-1666.

31. Morrissy RT. School screening for scoliosis. Spine. 1999;24:2584-2591.
32. Rogala EJ, Drummond DS, Gurr J. Scoliosis: incidence and natural history. A prospective epidemiological study. J Bone Joint Surg Am. 1978;60:173-176.

33. Ashworth MA, Hancock JA, Ashworth L, Tessier KA. Scoliosis screening. An approach to cost/benefit analysis. Spine. 1988;13: $1187-1188$

34. Pruijs JE, Hageman MA, Keessen W, Van der Meer R, Van Wieringen JC. Spinal rotation meter: development and comparison of a new device. Acta Orthop Belg. 1995;61:107-112.

35. Izatt MT, Bateman GR, Adam CJ. Evaluation of the iPhone with an acrylic sleeve versus the Scoliometer for rib hump measurement in scoliosis. Scoliosis. 2012;7:14.

36. Amendt LE, Auseellias KL, Eybers JL, Wadsworth CT, Nielsen DH, Weinstein SL. Validity and reliability testing of the Scoliometer. Phys Ther. 1990;70:108-117.

37. Grivas TB, Vasiliadis ES, Mihas C, Savvidou O. The effect of growth on the correlation between the spinal and rib cage deformity: implications on idiopathic scoliosis pathogenesis. Scoliosis. 2007;2:11.

38. Frerich JM, Hertzler K, Knott P, Mardjetko S. Comparison of radiographic and surface topography measurements in adolescents with idiopathic scoliosis. Open Orthop J. 2012;6:261-265.

39. Zubairi J. Applications of computer-aided raster stereography in spinal deformity detection. Image Vis Comput. 2002;20:319-324.

40. Chowanska J, Kotwicki T, Rosadzinski K, Sliwinski Z. School screening for scoliosis: can surface topography replace examination with scoliometer? Scoliosis. 2012;7:9.

41. Takasaki H. Moiré topography. Appl Opt. 1973;12:845-850.

42. Porto F, Gurgel JL, Russomano T, Farinatti Pde T. Moiré topography: characteristics and clinical application. Gait Posture. 2010;32: 422-424.

43. Pazos V, Cheriet F, Danserau J, Ronsky J, Zernicke RF, Labelle H. Reliability of trunk shape measurements based on 3-D surface reconstructions. Eur Spine J. 2007;16:1882-1891.

44. Grivas TB, Vasiliadis E, Mouzakis V, Mihas C, Koufopoulos G. Association between adolescent idiopathic scoliosis prevalence and age at menarche in different geographic latitudes. Scoliosis. 2006;1:9.

45. Kotwicki T, Chowanska J, Kinel E, Lorkowska M, Stryła W, Szulc A. Sitting forward bending position versus standing position for studying the back shape in scoliotic children. Scoliosis. 2007;2 Suppl 1: S34.

46. Chowanska J, Kotwicki T, Rosadzinski K. Comparison of standing and sitting position used in surface topography trunk assessment. Post Nauk Med. 2012;6:476-483. Polish.

47. Kotwicki T, Durmała J, Czaprowski D, et al. Conservative management of idiopathic scoliosis. Guidelines based on SOSORT 2006 consensus. Ortop Traumatol Rehabil. 2009;11:379-395.

48. Mordecai SC, Dabke HV. Efficacy of exercise therapy for the treatment of adolescent idiopathic scoliosis: a review of the literature. Eur Spine J. 2012;21:382-389.

49. Romano M, Minozzi S, Bettany-Saltikov J, et al. Exercises for adolescent idiopathic scoliosis. Cochrane Database Syst Rev. 2012;8: CD007837.

50. Lenssinck ML, Frijlink AC, Berger MY, Bierman-Zeinstra SM, Verkerk K, Verhagen AP. Effect of bracing and other conservative interventions in the treatment of idiopathic scoliosis in adolescents: a systematic review of clinical trials. Phys Ther. 2005;85: $1329-1339$.

51. Otman S, Kose N, Yakut Y. The efficacy of Schroths 3-dimensional exercise therapy in the treatment of adolescent idiopathic scoliosis in Turkey. Saudi Med J. 2005;26:1429-1435.

52. Dobosiewicz K, Durmala J, Czernicki K, Jendrzejek H. Pathomechanic basics of conservative treatment of progressive idiopathic scoliosis according to Dobosiewicz method based upon radiologic evaluation. Stud Health Technol Inform. 2002;91:336-341.

53. Negrini S, Antonini G, Carabalona R, Minozzi S. Physical exercises as a treatment for adolescent idiopathic scoliosis. A systematic review. Pediatr Rehabil. 2003;6:227-235. 
54. Negrini S, Fusco C, Minozzi S, Atanasio S, Zaina F, Romano M. Exercises reduce the progression rate of adolescent idiopathic scoliosis: results of a comprehensive systematic review of the literature. Disabil Rehabil. 2008;30:772-785.

55. Negrini S, Negrini A, Romano M, Verzini N, Negrini A, Parzini S. A controlled prospective study of SEAS.02 exercises in preparation to bracing for idiopathic scoliosis. Stud Health Technol Inform. 2006;123: 519-522.

56. Weiss HR, Goodall D. The treatment of adolescent idiopathic scoliosis (AIS) according to present evidence. A systematic review. Eur J Phys Rehabil Med. 2008;44:177-193.

57. Weiss HR, Hollaender M, Klein R. ADL based scoliosis rehabilitationthe key to an improvement of time-efficiency? Stud Health Technol Inform. 2006;123:594-598.

58. McIntire KL, Asher MA, Burton DC, Liu W. Treatment of adolescent idiopathic scoliosis with quantified trunk rotational strength training: a pilot study. J Spinal Disord Tech. 2008;21:349-358.

59. Weiss HR, Maier-Hennes A. Specific exercise in the treatment of scoliosisdifferential indication. Stud Health Technol Inform. 2008;135:173-190.

60. Negrini S, Grivas TB, Kotwicki T, et al. Why do we treat adolescent idiopathic scoliosis? What we want to obtain and to avoid for our patients. SOSORT 2005 consensus paper. Scoliosis. 2006;1:4.

61. Rigo M, Quera-Salva G, Villagrasa M, et al. Scoliosis intensive outpatient rehabilitation based on Schroth method. Stud Health Technol Inform. 2008;135:208-227.

62. Durmala J, Dobosiewicz K, Kotwicki T, Jendrzejek H. Influence of asymmetric mobilisation of the trunk on the Cobb angle and rotation in idiopathic scoliosis in children and adolescents. Ortop Traumatol Rehab. 2003;5:80-85.

63. Ferraro C, Masiero S, Venturin A. Effect of exercise therapy on mild idiopathic scoliosis. Eura Medicophys. 1998;34:25-31.

64. Weiss HR, Weiss G, Petermann F. Incidence of curvature progression in idiopathic scoliosis patients treated with scoliosis in-patient rehabilitation (SIR): an age- and sex-matched controlled study. Pediatr Rehabil. 2003;6:23-30.

65. Romano M, Negrini A, Parzini S, Negrini S. Scientific Exercises Approach to Scoliosis (SEAS): efficacy, efficiency and innovation. Stud Health Technol Inform. 2008;135:191-207.

66. Mamyama T, Kitagawal T, Takeshita K, Nakainura K. Side shift exercise for idiopathic scoliosis after skeletal maturity. Stud Health Technol Inform. 2002;91:361-364.

67. Weiss HR, Negrini S, Hawes M, et al. Physical exercises in the treatment of idiopathic scoliosis at risk of brace treatment - SOSORT consensus paper 2005. Scoliosis. 2006;1:6.

68. Zaina F, Negrini S, Atanasio S, Fusco C, Romano M, Negrini A. Specific exercises performed in the period of brace weaning can avoid loss of correction in Adolescent Idiopathic Scoliosis (AIS) patients: winner of SOSORT's 2008 award for best clinical paper. Scoliosis. 2009;4:8.

69. Negrini S, Grivas TB, Kotwicki T, Rigo M, Zaina F. Guidelines on "standards of management of idiopathic scoliosis with corrective braces in everyday clinics and in clinical research": SOSORT consensus 2008. Scoliosis. 2009;4:2.

70. Weiss HR. Rehabilitation of scoliosis patients with pain after surgery. Stud Health Technol Inform. 2002;88:250-253.

71. Barrios C, Perez-Encinas C. Significant ventilatory functional restriction in adolescents with mild or moderate scoliosis during maximal exercise tolerance test. Spine. 2005;30:1610-1615.

72. Czaprowski D, Kotwicki T, Biernat R, Urniaż J, Ronikier A. Physical capacity of girls with mild and moderate idiopathic scoliosis: influence of the size, length and number of curvatures. Eur Spine J. 2012;21: 1099-1105.

73. Martínez-Llorens J, Ramírez M, Colomina MJ, et al. Muscle dysfunction and exercise limitation in adolescent idiopathic scoliosis. Eur Respir J. 2010;36:393-400.

74. Newton PO, Perry A, Bastrom TP, et al. Predictors of change in postoperative pulmonary function in adolescent idiopathic scoliosis. A prospective study of 254 patients. Spine. 2007;32:1875-1882.
75. Dos Santos Alves VL, Stribulov R, Avanzi O. Impact of a physical rehabilitation program on the respiratory function of adolescents with idiopathic scoliosis. Chest. 2006;130:500-505.

76. Athanasopoulos S, Paxinos T, Tsafantakis E, Zachariou K, Chatziconstantinou $\mathrm{S}$. The effect of aerobic training in girls with idiopathic scoliosis. Scand J Med Sci Sports. 1999;9:36-40.

77. Weiss HR. The effect of an exercise program on vital capacity and rib mobility in patients with idiopathic scoliosis. Spine. 1991;16:88-93.

78. Negrini S, Zaina F, Romano M, Negrini A, Parzini S. Specific exercises reduce brace prescription in adolescent idiopathic scoliosis: a prospective controlled cohort study with worst-case analysis. J Rehabil Med. 2008;40:451-455.

79. Weiss HR. Influence of an in-patient exercise program on scoliotic curve. Ital J Orthop Traumatol. 1992;18:395-406.

80. Weiss HR, Weiss G. Curvature progression in patients treated with scoliosis in-patient rehabilitation - a sex and age matched controlled study. Stud Health Technol Inform. 2002;91:352-356.

81. Weiss HR, Klein R. Improving excellence in scoliosis rehabilitation: a controlled study of matched pairs. Pediatr Rehabil. 2006;9:190-200.

82. Negrini S, Atanasio S, Zaina F, Romano M, Parzini S, Negrini A. End-growth results of bracing and exercises for adolescent idiopathic scoliosis. Prospective worst-case analysis. Stud Health Technol Inform. 2008; 135:395-408

83. Guyatt GH, Oxman AD, Vist GE, et al. GRADE Working Group. GRADE: an emerging consensus on rating quality of evidence and strength of recommendations. BMJ. 2008;336:924-926.

84. Weiss HR, Lohschmidt K, el-Obeidi N, Verres C. Preliminary results and worst-case analysis of inpatient scoliosis rehabilitation. Pediatr Rehabil. 1997;1:35-40.

85. Shea KG, Stevens PM, Nelson M, Smith JT, Masters KS, Yandow S. A comparison of manual versus computer-assisted radiographic measurement. Intraobserver measurement variability for Cobb angles. Spine. 1998;23:551-555.

86. Adam CJ, Izatt MT, Harvey JR, Askin GN. Variability in Cobb angle measurements using reformatted computerized tomography scans. Spine. 2005;30:1664-1669.

87. Leszczewska J, Czaprowski D, Pawłowska P, Kolwicz A, Kotwicki T. Evaluation of the stress level of children with idiopathic scoliosis in relation to the method of treatment and parameters of the deformity. ScientificWorldJournal. 2012;2012:538409.

88. Rubery PT, Bradford DS. Athletic activity after spine surgery in children and adolescents: results of a survey. Spine. 2002;27:423-427.

89. Bunnell WP. The natural history of idiopathic scoliosis before skeletal maturity. Spine. 1986;11:773-776.

90. Lonstein JE, Carlson JM. The prediction of curve progression in untreated idiopathic scoliosis during growth. J Bone Joint Surg Am. 1984;66A:1061-1071.

91. Grivas TB, Dangas S, Samelis P, Maziotou C, Kandris K. Lateral spinal profile in school-screening referrals with and without late onset idiopathic scoliosis 10 degrees-20 degrees. Stud Health Technol Inform. 2002;91:25-31.

92. Asher MA, Burton DC. Adolescent idiopathic scoliosis: natural history and long term treatment effects. Scoliosis. 2006;1:2.

93. Gorman KF, Julien C, Moreau A. The genetic epidemiology of idiopathic scoliosis. Eur Spine J. 2012;21:1905-1919.

94. Ward K, Ogilvie JW, Singleton MV, Chettier R, Engler G, Nelson LM. Validation of DNA-based prognostic testing to predict spinal curve progression in adolescent idiopathic scoliosis. Spine. 2010;35: E1455-E1464. Response. Spine. 2011;35:1455-1464.

95. Negrini S, Zaina F, Atanasio S. Brace map, a proposal for a new classification of braces. Stud Health Technol Inform. 2008;140:299-302.

96. Kotwicki T, Cheneau J. Biomechanical action of a corrective brace on thoracic idiopathic scoliosis: Cheneau 2000 orthosis. Disabil Rehabil Assist Technol. 2008;3:146-153.

97. Zaborowska-Sapeta K, Kowalski IM, Kotwicki T, ProtasiewiczFałdowska H, Kiebzak W. Effectiveness of Chêneau brace treatment for idiopathic scoliosis: prospective study in 79 patients followed to skeletal maturity. Scoliosis. 2011;6:2. 
98. Pham VM, Herbaux B, Schill A, Thevenon A. Evaluation of the Chêneau brace in adolescent idiopathic scoliosis. Ann Readapt Med Phys. 2007;50:125-133.

99. Fayssoux RS, Cho RH, Herman MJ. A history of bracing for idiopathic scoliosis in North America. Clin Orthop Relat Res. 2010;468: 654-664.

100. Watts HG, Hall JE, Stanish W. The Boston brace system for the treatment of low thoracic and lumbar scoliosis by the use of a girdle without superstructure. Clin Orthop Relat Res. 1977;126:87-92.

101. Negrini S, Marchini G, Tessadri F. Brace technology thematic series - The Sforzesco and Sibilla braces, and the SPoRT (Symmetric, Patient oriented, Rigid, Three-dimensional, active) concept. Scoliosis. 2011;6:8.

102. Grivas TB, Kaspiris A. European braces widely used for conservative scoliosis treatment. Stud Health Technol Inform. 2010;158: $157-166$

103. Coillard C, Vachon V, Circo AB, Beausejour M, Rivard CH. Effectiveness of the SpineCor brace based on the new standardized criteria proposed by the Scoliosis Research Society for adolescent Idiopathic Scoliosis. J Pediatr Orthop. 2007;27:375-379.

104. Schiller JR, Thakur NA, Eberson CP. Brace management in adolescent idiopathic scoliosis. Clin Orthop Relat Res. 2010;468:670-678.

105. Wong MS, Cheng JC, Lam TP, et al. The effect of rigid versus flexible spinal orthosis on the clinical efficacy and acceptance of the patients with adolescent idiopathic scoliosis. Spine 2008;33:1360-1365.

106. Bulthuis GJ, Veldhuizen AG, Nijenbanning G. Clinical effect of continuous corrective force delivery in the non-operative treatment of idiopathic scoliosis: a prospective cohort study of the TriaC-brace. Eur Spine J. 2008;17:231-239.

107. Weiss HR, Werkmann M. Soft braces in the treatment of adolescent idiopathic scoliosis (AIS) - review of the literature and description of a new approach. Scoliosis. 2012;7:11.

108. Trivedi JM, Thomson JD. Results of Charleston bracing in skeletally immature patients with idiopathic scoliosis. J Pediatr Orthop. 2001;21 277-280.

109. Price CT, Scott DS, Reed FR, Sproul JT, Riddick MF. Nighttime bracing for adolescent idiopathic scoliosis with the Charleston bending brace: long-term follow-up. J Pediatr Orthop. 1997;17:703-707.

110. Katz DE, Richards BS, Browne RH, Herring JA. A comparison between the Boston brace and the Charleston bending brace in adolescent idiopathic scoliosis. Spine. 1997;22:1302-1312.

111. Blount WP. The Milwaukee brace in the treatment of the young child with scoliosis. Arch Orthop Unfallchir. 1964;56:363-369. German.

112. Andriacchi TP, Schultz AB, Belytschko TB, Dewald R. Milwaukee brace correction of idiopathic scoliosis. A biomechanical analysis and a retrospective study. J Bone Joint Surg Am. 1976;58:806-815.

113. Noonan KJ, Weinstein SL, Jacobson WC, Dolan LA. Use of the Milwaukee brace for progressive idiopathic scoliosis. J Bone Joint Surg Am. 1996;78A:557-567.

114. Lonstein JE, Winter RB. The Milwaukee brace for the treatment of adolescent idiopathic scoliosis. A review of one thousand and twenty patients. J Bone Joint Surg Am. 1994;76A:1207-1221.

115. Negrini S, Minozzi S, Bettany-Saltikov J, et al. Braces for idiopathic scoliosis in adolescents. Cochrane Database Syst Rev 2010;1:CD006850.

116. Nachemson AL, Peterson LE. Effectiveness of treatment with a brace in girls who have adolescent idiopathic scoliosis. A prospective, controlled study based on data from the Brace Study of the Scoliosis Research Society. J Bone Joint Surg Am. 1995;77A:815-822.

117. Rowe DE, Bernstein SM, Riddick MF, Adler F, Emans JB, GardnerBonneau D. A meta-analysis of the efficacy of non-operative treatments for idiopathic scoliosis. J Bone Joint Surg Am. 1997;79A:664-674.

118. Weinstein SL, Dolan LA, Cheng JC, Danielsson A, Morcuende JA. Adolescent idiopathic scoliosis. Lancet. 2008;371:1527-1537.

119. Lafage V, Schwab F, Patel A, Hawkinson N, Farcy JP. Pelvic tilt and truncal inclination two key radiographic parameters in the setting of adults with spinal deformity. Spine. 2009;34:E599-E606.
120. Bassett G, Bunnell W, MacEwen G. Treatment of idiopathic scoliosis with the Wilmington brace: results in patients with a 20-degree to 39 degree curve. J Bone Joint Surg Am. 1986;68A:602-605.

121. Little DG, Song KM, Katz D, Herring JA. Relationship of peak height velocity to other maturity indicators in idiopathic scoliosis in girls. J Bone Joint Surg Am. 2000;82A:685-693.

122. Kotwicki T, Negrini S, Grivas TB, et al. Methodology of evaluation of morphology of the spine and the trunk in idiophatic scoliosis and other spinal deformities -6 th SOSORT consensus paper. Scoliosis. 2009; 4:26

123. Malfair D, Flemming AK, Dvorak MF, et al. Radiographic evaluation of scoliosis: review. AJR Am J Roentgenol. 2010; 194(3 Suppl):S8-S22.

124. Perdriolle R. La Scoliose. Paris, France: Maloine SA; 1979.

125. Nash CL, Moe JH. A study of vertebral rotation. J Bone Joint Surg Am. 1969;A51:223-229.

126. Yilmaz G, Borkhuu B, Dhawale A, et al. Comparative analysis of hook, hybrid, and pedicle screw instrumentation in the posterior treatment of adolescent idiopathic scoliosis. J Pediatr Orthop. 2012;32:490-499.

127. Lenke LG, Betz RR, Harms J, et al. Adolescent idiopathic scoliosis: a new classification to determine extent of spinal arthrodesis. J Bone Joint Surg Am. 2001;83A:1169-1181.

128. Lenke LG, Betz RR, Clements D, et al. Curve prevalence of a new classification of operative adolescent idiopathic scoliosis: does classification correlate with treatment? Spine. 2002;27:604-611.

129. Suk SI, Kim WJ, Kim JH, et al. Indications of proximal thoracic curve fusion in thoracic adolescent idiopathic scoliosis. Spine. 2000;25: 2342-2349.

130. Harrington PR. Treatment of scoliosis: correction and internal fixation by spine instrumentation. J Bone Joint Surg Am. 1962;44:591-610.

131. Cotrel Y, Dubousset J. A new technique for segmental spinal osteosynthesis using the posterior approach. Rev Chir Orthop Reparatrice Appar Mot. 1984;70:489-494. French.

132. Potter BK, Kuklo TR, Lenke LG. Radiographic outcomes of anterior spinal fusion versus posterior spinal fusion with thoracic pedicle screws for treatment of Lenke type I adolescent idiopathic scoliosis curves. Spine. 2005;30:1859-1866.

133. Liljenqvist U, Lepsien U, Hackenberg L, Niemeyer T, Halm H. Comparative analysis of pedicle screw and hook instrumentation in posterior correction and fusion of idiopathic thoracic scoliosis. Eur Spine J. 2002;11:336-343.

134. Kim YJ, Lenke LG, Kim J, et al. Comparative analysis of pedicle screw versus hybrid instrumentation in posterior spinal fusion of adolescent idiopathic scoliosis. Spine. 2006;31:291-298.

135. Kim YJ, Lenke LG, Bridwell KH, et al. Comparative analysis of pedicle screw versus hook instrumentation in posterior spinal fusion of adolescent idiopathic scoliosis: a matched cohort analysis. Spine. 2004;29:2040-2048.

136. Cheng I, Kim Y, Gupta MC, Bridwell KH, Hurford RK. Apical sublaminar wires versus pedicle screws - which provides better results for surgical correction of adolescent idiopathic scoliosis? Spine. 2005;30:2104-2112.

137. Suk SI, Kim JH, Kim SS, Lee JJ, Han YT. Thoracoplasty in thoracic adolescent idiopathic scoliosis. Spine. 2008;33:1061-1067.

138. Freeman BL. Scoliosis and kyphosis. In: Canale ST, Beaty JH, editors. Campbell's Operative Orthopaedics. Philadelphia, PA: Mosby Elsevier; 2008.

139. Chen SH, Huang TJ, Lee YY, Hsu RWW. Pulmonary function after thoracoplasty in adolescent idiopathic scoliosis. Clin Orthop Relat Res. 2002;399:152-161.

140. Haher TR, Gorup JM, Shin TM, et al. Results of the scoliosis research society instrument for evaluation of surgical outcome in adolescent idiopathic scoliosis - a multicenter study of 244 patients. Spine. 1999;24:1435-1440.

141. Wilson PL, Newton PO, Wenger DR, et al. A multicenter study analyzing the relationship of a standardized radiographic scoring system of adolescent idiopathic scoliosis and the Scoliosis Research Society outcomes instrument. Spine. 2002;27:2036-2040. 
142. Asher MA, Lai SM, Burton DC. Further development and validation of the Scoliosis Research Society (SRS) outcomes instrument. Spine. 2000;25:2381-2386

143. Asher M, Lai SM, Burton D, Manna B. The reliability and concurrent validity of the Scoliosis Research Society-22 patient questionnaire for idiopathic scoliosis. Spine. 2003;28:63-69.

144. Asher MA, Lai SM, Glattes C, Burton DC, Alanay A, Bago J. Refinement of the SRS-22 health-related quality of life questionnaire function domain. Spine. 2006;31:593-597.

145. Lai SM, Burton, Asher MA, Carlson BB. Converting SRS-24, SRS-23, and SRS-22 to SRS-22r: establishing conversion equations using regression modeling. Spine. 2011;36:E1525-E1533.

146. Asher M, Lai SM, Burton D, Manna B. The influence of spine and trunk deformity on preoperative idiopathic scoliosis patients' health-related quality of life questionnaire responses. Spine. 2004;29:861-868.

147. Tones M, Moss N, Polly DW Jr. A review of quality of life and psychosocial issues in scoliosis. Spine. 2006;31:3027-3038.

148. Climent JM, Bago J, Ey A, Perez-Grueso FJS, Izquierdo E. Validity of the Spanish version of the Scoliosis Research Society-22 (SRS-22) patient questionnaire. Spine. 2005;30:705-709.

149. Bago J, Climent JM, Ey A, Perez-Grueso FJS, Izquierdo E. The Spanish version of the SRS-22 patient questionnaire for idiopathic scoliosis - transcultural adaptation and reliability analysis. Spine. 2004;29:1676-1680

150. Watanabe K, Hasegawa K, Hirano T, Uchiyama S, Endo N. Use of the scoliosis research society outcomes instrument to evaluate patient outcome in untreated idiopathic scoliosis patients in Japan - Part I: Comparison with nonscoliosis group: preliminary/limited review in a Japanese population. Spine. 2005;30:1197-1201.

151. Watanabe K, Hasegawa K, Hirano T, Uchiyama S, Endo N. Use of the Scoliosis Research Society Outcomes Instrument to evaluate patient outcome in untreated idiopathic scoliosis patients in Japan. Part II: Relation between spinal deformity and patient outcomes. Spine. 2005;30:1202-1205

152. Monticone M, Carabalona R, Negrini S. Reliability of the Scoliosis Research Society-22 questionnaire (Italian version) in mild adolescent vertebral deformity. Eur Med Phys. 2004;40:191-197.

153. Zhao L, Zhang Y, Sun X, Du Q, Shang L. The Scoliosis Research Society-22 questionnaire adapted for adolescent idiopathic scoliosis patients in China: reliability and validity analysis. J Child Orthop. 2007;1:351-355.

154. Bunge EM, Juttmann RE, de Kleuver M, van Biezen FC, de Koning HJ; NESCIO Group. Health-related quality of life in patients with adolescent idiopathic scoliosis after treatment: short-term effects after brace or surgical treatment. Eur Spine J. 2007;16:83-89.

155. Lee JS, Lee DH, Suh KT, Kim JI, Lim JM, Goh TS. Validation of the Korean version of the Scoliosis Research Society-22 questionnaire. Eur Spine J. 2011;20:1751-1756.

156. Alanay A, Cil A, Berk H, et al. Reliability and validity of adapted Turkish version of Scoliosis Research Society-22 (SRS-22) questionnaire. Spine. 2005;30:2464-2468.

157. Misterska E, Glowacki M, Harasymczuk J. Polish adaptation of Bad Sobernheim Stress Questionnaire-Brace and Bad Sobernheim Stress Questionnaire-Deformity. Eur Spine J. 2009;18:1911-1919.

158. Adobor RD, Rimeslatten S, Keller A, Brox JI. Repeatability, reliability, and concurrent validity of the Scoliosis Research Society-22 Questionnaire and EuroQol in patients with adolescent idiopathic scoliosis. Spine. 2010;35:206-209.

159. Danielsson AJ, Hasserius R, Ohlin A, Nachemson AL. Health-related quality of life in untreated versus brace-treated patients with adolescent idiopathic scoliosis: a long-term follow-up. Spine. 2010;35: 199-205.
160. Beauséjour M, Joncas J, Goulet L, et al. Reliability and validity of adapted French Canadian Version of Scoliosis Research Society Outcomes Questionnaire (SRS-22) in Quebec. Spine. 2009;34:623-628.

161. Antonarakos PD, Katranitsa L, Angelis L, et al. Reliability and validity of the adapted Greek version of Scoliosis Research Society-22 (SRS22) questionnaire. Scoliosis. 2009;4:14.

162. Hashimoto H, Sase T, Arai Y, Maruyama T, Isobe K, Shouno Y. Validation of a Japanese version of the Scoliosis Research Society-22 patient questionnaire among idiopathic scoliosis patients in Japan. Spine. 2007;32:E141-E146.

163. Mousavi SJ, Mobini B, Mehdian H, et al. Reliability and validity of the Persian version of the Scoliosis Research Society-22r Questionnaire. Spine. 2010;35:784-789.

164. Rosanova GCL, Gabriel BS, Camarini PMF, Gianini PES, Coelho DM, Oliveira AS. Concurrent validity of the Brazilian version of SRS-22r with Br-SF-36. Rev Bras Fisioter. 2010;14:121-126.

165. Bago J, Climent JM, Ey A, Perez-Grueso FJ, Izquierdo E. Letter to the editor. Re: Asher MA, Lai SM, Glattes RC, et al. Refinement of the SRS-22 health-related quality of life questionnaire function domain. Spine. 2006;31:1758.

166. Monticone M, Baiardi P, Calabrò D, Foti C. Development of the Italian version of the Revised Scoliosis Research Society-22 Patient Questionnaire, SRS-22r-I cross-cultural adaptation, factor analysis, reliability, and validity. Spine. 2010;35:E1412-E1417.

167. Feise RJ, Donaldson S, Crowther ER, Menke JM, Wright JG. Construction and validation of the scoliosis quality of life index in adolescent idiopathic scoliosis. Spine. 2005;30:1310-1315.

168. Climent JM, Sanchez J. Impact of the type of brace on the quality of life of adolescents with spine deformities. Spine. 1999;24:1903-1908.

169. Ugwonali OF, Lomas G, Choe JC, et al. Effect of bracing on the quality of life of adolescents with idiopathic scoliosis. Spine J. 2004;4: 254-260.

170. Freidel K, Petermann F, Reichel D, Steiner A, Warschburger P, Weiss HR. Quality of life in women with idiopathic scoliosis. Spine. 2002;27:E87-E91.

171. Vasiliadis E, Grivas TB, Gkoltsiou K. Development and preliminary validation of Brace Questionnaire (BrQ): a new instrument for measuring quality of life of brace treated scoliotics. Scoliosis. 2006;1:7.

172. Kinel E, Kotwicki T, Podolska A, Białek M, Stryła W. Polish validation of Brace Questionnaire. Eur Spine J. 2012;21:1603-1608.

173. Botens-Helmus C, Klein R, Stephan C. The reliability of the Bad Sobernheim Stress Questionnaire (BSSQbrace) in adolescents with scoliosis during brace treatment. Scoliosis. 2006;1:22.

174. Bago J, Sanchez-Raya J, Sanchez Perez-Grueso FJS, Climent JM. The Trunk Appearance Perception Scale (TAPS): a new tool to evaluate subjective impression of trunk deformity in patients with idiopathic scoliosis. Scoliosis. 2010;5:6.

175. Carreon LY, Sanders JO, Polly DW, et al. Spinal Appearance Questionnaire: factor analysis, scoring, reliability, and validity testing. Spine. 2011;36:E1240-E1244.

176. Rinella A, Lenke L, Peelle M, Edwards C, Bridwell KH, Sides B. Comparison of SRS questionnaire results submitted by both parents and patients in the operative treatment of idiopathic scoliosis. Spine. 2004;29:303-310.

177. Knott P, Anderson C, Werner M, Wilson H, Speers D. The effects of scoliosis bracing on parent and child perception of adolescent's quality of life. In: The SOSORT meeting booklet. Ninth International Conference on Conservative Management of Spinal Deformities, Seventh SOSORT meeting, Milan, Italy, May 10-12, 2012. 
Adolescent Health, Medicine and Therapeutics

Dovepress

\section{Publish your work in this journal}

Adolescent Health, Medicine and Therapeutics is an international, peer-reviewed, open access journal focusing on health, pathology, and treatment issues specific to the adolescent age group. All aspects of health maintenance, preventative measures and disease treatment interventions are addressed within the journal and practitioners from all disciplines are invited to submit their work as well as healthcare researchers and patient support groups.. The manuscript management system is completely online and includes a very quick and fair peerreview system. Visit http://www.dovepress.com/testimonials.php to read real quotes from published authors.

Submit your manuscript here: http://www.dovepress.com/adolescent-health-medicine-and-therapeutics-journal 